\title{
Comparação entre dois métodos de suplementação de ferro para a prevenção da anemia ferropriva no primeiro ano de vida em crianças nascidas prematuras
}

\author{
Comparison between two methods of supplemental iron intake \\ to prevent iron deficiency anemia in the first year of life of preterm infants
}

\author{
Gisele M.C. Vianna ${ }^{1}$, Arthur L. Gonçalves ${ }^{2}$
}

\section{Resumo}

Objetivo: comparar dois métodos de suplementação de ferro (fórmula fortificada versus gotas de sulfato ferroso) para prevenir a anemia por carência de ferro em prematuros.

Métodos: foram incluídos sessenta e seis lactentes, nascidos com até 36 semanas de gestação e peso de $1.000 \mathrm{~g}$ até $2.000 \mathrm{~g}$. Quarenta crianças completaram o seguimento previsto, do $2^{\circ}$ ao $12^{\circ}$ mês de vida, divididas em dois grupos - grupo A: 20 lactentes que receberam fórmula fortificada, com $11 \mathrm{mg} \mathrm{Fe/litro;} \mathrm{e} \mathrm{grupo} \mathrm{B:} 20$ lactentes alimentados com leite de vaca em pó integral, suplementado com sulfato ferroso em gotas $(2 \mathrm{mg} \mathrm{Fe} / \mathrm{kg} / \mathrm{dia})$. Foi coletado sangue aos dois e 12 meses de idade $(2 \mathrm{ml})$ para dosagens de hemoglobina, hematócrito, ferro sérico, TIBC, ferritina sérica e protoporfirina eritrocitária livre; e aos seis meses $(1 \mathrm{ml})$, para hemoglobina e hematócrito. Para análise estatística, usou-se o teste "t" de Student e o do "qui-quadrado" $\left(\chi^{2}\right)$, com $\mathrm{p}<0,05$.

Resultados: não houve diferenças significativas entre os grupos em relação ao peso aos dois, seis e 12 meses de idade, nem quanto ao ganho ponderal global. Aos dois meses, os níveis de hemoglobina, hematócrito, ferro sérico e saturação de TIBC não diferiam significativamente entre os dois grupos, mas aos 12 meses o grupo que recebeu a fórmula fortificada apresentou níveis significativamente superiores desses indicadores ( $\mathrm{p}<0,05)$, o que já tinha sido observado aos seis meses em relação ao hematócrito e hemoglobina. A protoporfirina eritrocitária livre permaneceu estável nas crianças que receberam a fórmula, tendo aumentado do $2^{\circ}$ para o $12^{\circ}$ mês no grupo $\mathrm{B}(\mathrm{p}<0,05)$. Os níveis de ferritina de ambos os grupos eram normais aos dois meses e diminuíram acentuadamente aos 12 meses, mas apenas quatro (20\%) crianças do grupo A apresentaram níveis $\leq 10 \mathrm{ng} / \mathrm{ml}$, contra doze $(60 \%)$ do grupo B $(\mathrm{p}<0,02)$.

Conclusão: a fórmula fortificada com ferro mostrou-se mais eficaz para prevenir a carência de ferro e a anemia tardia da prematuridade, comparada à administração diária de ferro em gotas.

J Pediatr (Rio J) 2002; 78(4): 315-20: prematuro, deficiência de ferro, anemia, prevenção e controle.

\begin{abstract}
Objective: to compare two methods of iron supplementation (fortified formula versus medicinal iron drops) to prevent iron deficiency anemia in preterm infants.

Methods: sixty six premature infants weighing between 1000$2000 \mathrm{~g}$ were included in the study. Forty infants completed the whole follow-up period, divided into 2 groups: Group A: 20 infants fed with iron fortified formula (11 mg Fe/l); Group B: 20 infants fed with powder cow's milk supplemented with $2 \mathrm{mg} \mathrm{Fe} / \mathrm{kg} /$ day, as drops of ferrous sulfate. At two and 12 months $2 \mathrm{ml}$ of blood were collected to measure hemoglobin, hematocrit, serum iron, total iron binding capacity (TIBC), serum ferritin and free erythrocyte porphyrins. At the $6^{\text {th }}$ month, $1 \mathrm{ml}$ of blood was drawn for hemoglobin and hematocrit determinations. Statistical analysis used the Student $t$ test and $\chi^{2}$, with $\mathrm{p}<0.05$.
\end{abstract}

Results: there were no significant differences between the groups in terms of body weight and weight gain; hemoglobin, hematocrit, serum iron levels and TIBC saturation indexes were similar in both groups at two months but significantly higher in group A at 12 months of age, while free erythrocite porphyrins levels remained stable in Group A and increased significantly in Group B $(p<0.05)$. Ferritin levels were normal in both groups at two months and declined sharply by 1 year of age, but only $4(20 \%)$ infants of Group A showed levels $\leq 10 \mathrm{ng} / \mathrm{ml}$, against $12(60 \%)$ of the Group B $(\mathrm{p}<0.02)$.

Conclusions: the iron fortified formula was significantly more efficient than medicinal iron drops to prevent iron deficiency anemia of preterm infants.

J Pediatr (Rio J) 2002; 78 (4): 315-20: preterm infant, iron deficiency, anemia, prevention and control.

1. Mestre em Pediatria pela Faculdade de Medicina de Ribeirão Preto - USP. Professora Assistente de Pediatria da Faculdade de Medicina de Catanduva, SP.

2. Professor Titular do Departamento de Puericultura e Pediatria da Faculdade de Medicina de Ribeirão Preto - USP.

Fontes financiadoras: CNPq, CAPES

Artigo submetido em 09.10.01, aceito em 08.05.02. 


\section{Introdução}

A deficiência de ferro, isoladamente, é ainda a mais comum deficiência nutricional no mundo, atingindo cerca de 1 bilhão de pessoas, principalmente lactentes, préescolares e mulheres, inclusive nos países considerados desenvolvidos ${ }^{1,2}$.

A forma mais grave dessa deficiência é a anemia, que surge após a exaustão dos depósitos de ferro do indivíduo, e que leva à queda do seu rendimento físico e intelectual, particularmente nas crianças, cuja recuperação, mesmo após a correção da anemia, nem sempre é obtida ${ }^{3-5}$.

Isso é particularmente temível em lactentes nascidos prematuramente e/ou de muito baixo peso, tendo em vista que seu patrimônio de ferro ao nascer é pequeno, e limitado ao existente em seus eritrócitos, podendo ser depletado rapidamente se não receber suplementação regular e suficiente a partir do primeiro mês de vida, porque suas taxas de crescimento e aumento da volemia são elevados, e o aporte de ferro alimentar, inclusive pelo leite materno, é insuficiente $^{6}$.

Estudos da Organização Mundial da Saúde (OMS) mostram que a incidência de anemia ferropriva em lactentes e crianças no mundo é em torno de $36 \%$, variando de país para país e mesmo de região para região do mesmo país, com cifras médias de $12 \%$ nas regiões mais desenvolvidas do planeta, e de até $67 \%$ em algumas regiões da Ásia $\mathrm{Central}^{2}$. No Brasil, em levantamentos realizados no estado de São Paulo, nos anos de 1992 e 1994, as cifras de crianças anêmicas na faixa etária de 6 a 24 meses foram de $59 \%$ e $57 \%$ respectivamente ${ }^{7,8}$, e as de prematuros seguramente superam amplamente esses percentuais, sendo relatado nível de 73,9\% em crianças prematuras aos 12 meses de idade, mesmo com seguimento ambulatorial regular, recebendo gratuitamente ferro medicinal e orientação para administrar $2 \mathrm{mg} \mathrm{Fe} / \mathrm{kg} / \mathrm{dia}^{9}$.

Discute-se, ainda, qual a quantidade mais adequada de ferro para prevenir a anemia tardia da prematuridade. A Academia Americana de Pediatria (AAP), através do seu Comitê de Nutrição (ESPGAN), e a Sociedade Européia de Gastrenterologia Pediátrica e Nutrição recomendam a suplementação de $2 \mathrm{mg}$ de ferro por quilo, por dia, a todos os prematuros, a partir do segundo mês ou após a alta hospitalar e até o final do primeiro ano de vida, independente do peso ao nascer ${ }^{10,11}$, o que aparentemente é insuficiente para suprir as necessidades de recém-nascidos de muito baixo peso (RNMPB - peso $<1.500 \mathrm{~g}$ ) e de prematuros extremos $(<1.000 \mathrm{~g})$, para os quais foram sugeridas doses de até $4 \mathrm{mg} / \mathrm{kg} /$ dia durante todo o primeiro ano de vida ${ }^{12,13}$. Contudo, influi sobre a eficácia da profilaxia não só a dose diária administrada, mas também a biodisponibilidade do ferro oferecido, a concomitância com outros alimentos e, fundamentalmente, a maneira e a regularidade com que é $\operatorname{administrado}^{14}$.

Em nosso país, já foi demonstrado que o fornecimento de leite enriquecido com ferro diminui significativamente os índices de anemia ferropriva de lactentes nascidos a termo e pré-escolares de populações carentes ${ }^{15}$, o que não se observa com prematuros a cujas mães é fornecido regular e gratuitamente ferro medicinal, na forma de sulfato ferroso, sal com excelente biodisponibilidade, para administração em gotas, diariamente ${ }^{9}$, e ainda não se dispõe de fórmula láctea infantil fortificada com ferro especialmente desenvolvida para prematuros, só existindo para nascidos a termo.

Foi, pois, objetivo deste estudo, verificar qual a melhor maneira de se administrar ferro para profilaxia da carência de ferro e prevenção da anemia tardia da prematuridade, se através de fórmula infantil fortificada com ferro $(11 \mathrm{mg}$ de ferro por litro) ou de sulfato ferroso, na forma de gotas, na dose de $2 \mathrm{mg}$ de ferro/kg/dia.

\section{Casuística e métodos}

Foram incluídos, no período de outubro de 1996 a novembro de 1998, 66 crianças de ambos os sexos, nascidas prematuramente, com idade gestacional inferior a 36 semanas e peso ao nascer entre 1.000 e 2.000 gramas. Quarenta crianças completaram o seguimento previsto, de 2 meses até 12 meses de idade. A idade gestacional foi calculada pela data da última menstruação e pelo método de Capurro et al. ${ }^{16}$, tendo as 40 crianças sido alocadas em dois grupos, conforme descrito a seguir.

Grupo A: 20 lactentes, cinco em cada faixa ponderal, que receberam fórmula infantil fortificada com $11 \mathrm{mg}$ de ferro/litro (NAN2 ${ }^{\circledR}$ ) na concentração a 13,2\% (1:30).

Grupo B: 20 lactentes que receberam leite de vaca integral em pó, nas diluições adequadas à idade, suplementado com sulfato ferroso, em gotas, na dose de $2 \mathrm{mg}$ de ferro/ $\mathrm{kg} / \mathrm{dia}$, e polivitaminas.

A alocação para os grupos deu-se por sorteio, aos dois meses de vida, estratificando-se os 20 lactentes de cada grupo em quatro faixas de peso ao nascer $(1.000 \mathrm{~g}-1.250 \mathrm{~g}$, $1.251 \mathrm{~g}-1.500 \mathrm{~g}, 1.501 \mathrm{~g}-1.750 \mathrm{~g}$ e $1.751 \mathrm{~g}-2.000 \mathrm{~g}$ ) da seguinte forma: dispondo-se de um lactente de $1.200 \mathrm{~g}$ de peso de nascimento, por exemplo, sorteava-se o tipo de leite a receber e o próximo lactente da mesma faixa ponderal era alocado automaticamente para o outro grupo, ou seja, se a primeira criança estava no grupo $\mathrm{A}$, a seguinte da mesma faixa ponderal iria para o B, pareando-se os ingressos, e assim sucessivamente.

Só foram incluídas crianças hígidas, moradoras no município de Ribeirão Preto ou em cidades circunvizinhas, que tiveram boa evolução pós-natal, não portadoras de doenças crônicas que pudessem afetar seu desenvolvimento, e cujas mães já não as amamentavam, tinham limitações financeiras para adquirir fórmulas infantis e que recorreriam ao Serviço Assistencial de seus municípios, que fornecem leite de vaca tipo $\mathrm{C}$ ou em pó integral, dependendo da disponibilidade do momento. 
Antes do sorteio, um dos autores (GV) detalhava à mãe e ao pai ou responsável da criança o projeto, seus objetivos, exames a serem colhidos, eventuais benefícios e compromissos mútuos, só incluindo-a se houvesse concordância e assinatura do termo de consentimento informado submetido à Comissão de Ética em Pesquisa do hospital, que aprovou o projeto previamente.

A suplementação com sulfato ferroso em gotas era orientada pessoalmente por um dos autores, na base de duas gotas por quilo por dia, fornecendo-se o medicamento e o polivitamínico gratuitamente às mães do grupo $\mathrm{B}$.

A fórmula infantil e o leite em pó foram fornecidos às mães, sob rígido controle, com visitas mensais regulares e às vezes sem prévio aviso, de uma auxiliar de pesquisa, para recolher as latas vazias, deixar quantidade suficiente para um mês de consumo e se assegurar que as prescrições estavam sendo obedecidas. A fórmula fortificada com ferro foi doada pela Cia. Nestlé, e o leite em pó integral era adquirido no comércio local, com recursos disponibilizados pelo CEPP-Centro de Estudos e Pesquisas Pediátricas.

Durante o período de internação, as crianças dos dois grupos obedeceram o mesmo esquema de alimentação. As de maior peso e vigorosas eram levadas ao seio materno, e as demais recebiam, inicialmente, leite da própria mãe ou de banco de leite humano, com aumento gradativo de volume, de acordo com suas condições clínicas e aceitação. Os neonatos de peso inferior a $1.500 \mathrm{~g}$, ao atingir $100 \mathrm{ml} / \mathrm{kg} /$ dia, passavam a receber leite humano adicionado de fórmula especial para pré-termo $\left(\right.$ PRENAN $\left.^{\circledR}\right)$, volume a volume, na diluição a $16,3 \%$ (1:25) até atingir $1.800 \mathrm{~g}$, quando transicionavam para fórmula infantil se suas mães não tivessem conseguido manter a lactação.

A alta hospitalar era dada quando as crianças estivessem ganhando peso regularmente e pesando cerca de $2.000 \mathrm{~g}$, tendo ocorrido entre o $11^{\circ} \mathrm{e}$ o $30^{\circ}$ dia de vida (médias de 18 dias no grupo A e 20 no grupo B) nos nascidos com peso acima de $1.500 \mathrm{~g}$, e entre o $23^{\circ}$ e o $50^{\circ}$ dia de vida (médias de 42 e 39 dias nos grupos A e B, respectivamente) nos com peso ao nascer até $1.500 \mathrm{~g}$, sem diferenças estatisticamente significantes entre os grupos $(\mathrm{p}=0,62)$.

Após a alta, às crianças desmamadas, prescrevia-se fórmula infantil padronizada no serviço, na diluição 1:30 e volume entre $160-180 \mathrm{ml} / \mathrm{kg} / \mathrm{dia}$.

A unidade de prematuros não faz uso de eritropoetina e só transfunde sangue a neonatos fora da UTI neonatal se esses apresentarem hemoglobina inferior a $8 \mathrm{~g} / \mathrm{dl}$ e/ou taquicardia e ganho ponderal insuficiente. O número de transfusões de papa de hemácias nos dois grupos durante a internação não diferiu significativamente, só tendo sido necessárias em nascidos com menos de $1.500 \mathrm{~g}$, nas seguintes cifras: quatro crianças do grupo A e seis do grupo B, variando de um a cinco transfusões e médias de 1,3 e 1,4 por criança dos grupos A e B, respectivamente $(\mathrm{p}=0,89)$.

O leite de vaca em pó era diluído a $10 \%$ até o sexto mês, e a $15 \%$ (integral) após essa idade, sempre acrescido de 5\% de sacarose, conforme nosso protocolo de alimentação. A fórmula fortificada com ferro era oferecida na concentração de 13,2\% (1:30), no volume de 160-180 ml/kg/dia.

A introdução de alimentos sólidos foi idêntica nos dois grupos, iniciando com papa de frutas no terceiro mês de idade corrigida, correspondente, em média, ao quinto mês de idade cronológica. Papa de cereais era introduzida, em quantidades mínimas, 15 dias após, e papa de vegetais após o quarto mês de idade corrigida ou sexto mês de idade cronológica, dependendo do peso. Caldo de carne foi introduzido no sexto mês de idade corrigida, e gema de ovo cozido e raspada depois de 15-30 dias, conforme proposto por Woiski ${ }^{17}$

Todas as 40 crianças foram avaliadas clinicamente pela autora (G.V.) com 2 meses \pm 3 dias de vida, e tiveram seus retornos agendados mês a mês no primeiro semestre de vida, e a cada dois meses, do sexto ao $12^{\circ}$ mês de idade.

Aos dois meses de idade, colhiam-se $2 \mathrm{ml}$ de sangue para as dosagens de hemoglobina, hematócrito, glóbulos vermelhos, reticulócitos, ferro sérico, TIBC (total iron binding capacity), ferritina sérica e protoporfirina eritrocitária livre (PEL). Aos seis meses, colhia-se $1 \mathrm{ml}$ para dosagens de hemoglobina, hematócrito, glóbulos vermelhos e reticulócitos, e aos 12 meses de idade repetiam-se as mesmas dosagens laboratoriais feitas aos dois meses ${ }^{18}$. As quantificações de hemoglobina, hematócrito, glóbulos vermelhos e reticulócitos foram feitas em contador eletrônico (Coulter ${ }^{\circledR}$ STKS), que era calibrado diariamente. As dosagens de ferro e TIBC foram feitas em duplicata, pelo método de Ramsay ${ }^{19}$, adaptado para microamostras por Faggioni ${ }^{20}$. A PEL foi dosada pelo método fluorimétrico descrito por Piomelli $^{21}$, e a ferritina por radioimunoensaio.

O tamanho mínimo da amostra suficiente para conclusões relativas aos níveis de hemoglobina e hematócrito, baseado na média e desvio-padrão populacional dessa faixa etária, com limite de confiança de $90 \%(\beta=10 \%)$ e nível de significância $(\alpha)$ de 5\% (p <0,05), foi calculado em 16 crianças para cada grupo, ou quatro crianças em cada faixa ponderal, tendo-se utilizado o teste $t$ de Student para comparação das médias dos grupos, e o qui-quadrado $\left(\chi^{2}\right)$ para comparação de proporções ${ }^{22}$.

\section{Resultados}

Para se conseguir 20 crianças em cada grupo, foi necessário incluir 35 prematuros no grupo $\mathrm{A}$, e 31 no grupo $\mathrm{B}$, com perda de 15 e 11 lactentes em cada um, respectivamente.

As causas das perdas foram as seguintes:

- no grupo A: oito crianças por mudança de domicílio e abandono do seguimento, quatro por não seguirem as orientações dietéticas corretamente, e três porque suas mães também administraram sulfato ferroso em gotas, contrariando orientação recebida; 
- no grupo B: nove crianças por mudança de domicílio e abandono do seguimento, uma por ter recebido leite integral e fórmulas infantis não prescritas, e uma por ter apresentado pneumonias de repetição.

Os grupos eram comparáveis ao nascer, pois o peso médio das crianças do grupo A foi de $1.496 \mathrm{~g}( \pm 73 \mathrm{~g})$ e do grupo $\mathrm{B}$ de $1.498 \mathrm{~g}( \pm 64 \mathrm{~g})$, e as idades gestacionais de 32,7 $( \pm 0,4)$ semanas e $33,1( \pm 0,4)$ semanas, respectivamente $(\mathrm{p}=0,45)$.

A Tabela 1 apresenta as médias e os erros-padrão das médias de peso dos dois grupos de crianças no início da avaliação (dois meses), aos seis meses e 12 meses de idade, bem como o incremento médio de peso entre o $2^{\circ}$ e $12^{\circ}$ meses de idade $(\Delta 12 \mathrm{~m}-2 \mathrm{~m})$, podendo-se verificar que não houve diferenças estatisticamente significantes entre os dois grupos, tendo ambos os grupos triplicado o peso inicial.

A Tabela 2 apresenta os valores médios e respectivos erros-padrão das médias de hemoglobina e hematócrito nos dois grupos, podendo-se verificar que no início (dois meses) não havia diferença entre eles, mas já aos seis meses as crianças do grupo A, que receberam a fórmula fortificada com ferro, apresentavam médias significativamente superiores às do grupo $\mathrm{B}$, com alta significância estatística, $\mathrm{o}$ que se acentuou aos 12 meses.

A Tabela 3 apresenta os níveis séricos médios ( \pm erropadrão) do ferro, TIBC e protoporfirina eritrocitária livre (PEL) dos dois grupos, podendo-se verificar que aos dois meses não havia diferenças estatisticamente signficantes entre os grupos. Aos 12 meses, o nível do ferro sérico nas crianças do grupo B (ferro em gotas) diminuiu e a PEL aumentou, com diferenças estatisticamente significantes entre os grupos, enquanto o TIBC subiu ligeiramente em ambos, mas sem diferenças significativas entre eles.

As taxas de saturação do TIBC aos dois meses eram bem próximas nos dois grupos $(\mathrm{A}=30,4 \pm 2,8 ; \mathrm{B}=27,4 \pm 2,1$; $\mathrm{p}=0,40)$, mas aos 12 meses as crianças que receberam a fórmula fortificada apresentaram taxas normais $(23,3 \pm$ $1,83)$ e significativamente superiores às do grupo que recebeu ferro em gotas $(12,5 \pm 2,06), p=0,0026$.

Quanto à ferritina, verificou-se que aos dois meses seus níveis eram normais nos dois grupos, de $98,4 \pm 12,2 \mathrm{ng} / \mathrm{ml}$ no grupo $\mathrm{A}$, e $161,3 \pm 39,0 \mathrm{ng} / \mathrm{ml}$ no grupo $\mathrm{B}(\mathrm{p}>0,05)$, tendo diminuído em ambos os grupos aos 12 meses, mas apenas quatro crianças $(20 \%)$ do grupo A apresentaram níveis abaixo de $10 \mathrm{ng} / \mathrm{ml}$, contra $12(60 \%)$ do grupo B, diferença esta altamente significante no teste do qui-quadrado $\left(\chi^{2}=6,66, p<0,02\right)$.

\section{Discussão}

A longa duração deste estudo, de pouco mais de três anos, foi decorrência das características da população estudada, do tempo de seguimento clínico-laboratorial e do tamanho amostral necessário à consecução dos objetivos propostos, tendo sido semelhante ao de outros autores ${ }^{9,24,25}$, em trabalhos comparáveis e com seguimentos de dois a quatro meses mais curtos e, portanto, de mais fácil e rápida conclusão.

Tabela 1 - Peso (g) aos 2, 6 e 12 meses de idade, (média \pm erro-padrão)

\begin{tabular}{lccccc}
\hline Grupos & $\mathbf{N}$ & $\mathbf{2 m}$ & $\begin{array}{c}\text { Idade (meses) } \\
\mathbf{6 m}\end{array}$ & $\mathbf{1 2 m}$ & $\mathbf{\Delta ( 1 2 m} \mathbf{- 2 m})$ \\
\hline $\begin{array}{l}\text { A - Fórmula fortificada } \\
\quad \text { com ferro }\end{array}$ & 20 & $2.930 \pm 117,5$ & $6.123 \pm 195,2$ & $8.660 \pm 238,6$ & $5.730 \pm 200$ \\
$\begin{array}{l}\text { B - Leite integral + } \\
\text { 2mg de ferro/kg/dia }\end{array}$ & 20 & $2.650 \pm 95,4$ & $5.635 \pm 176,5$ & $8.290 \pm 227,1$ & $5.640 \pm 214$ \\
$\mathrm{p}$ & & 0,06 & 0,06 & 0,26 & 0,76 \\
\hline
\end{tabular}

$\mathrm{N}=$ número de crianças $\mathrm{m}=$ meses.

Tabela 2 - Hemoglobina (g/dl) e hematócrito(\%) aos 2, 6 e 12 meses de idade (média \pm erro-padrão)

\begin{tabular}{|c|c|c|c|c|c|c|c|}
\hline Grupos & $\mathbf{N}$ & 2 meses & $\begin{array}{l}\text { Idade } \\
6 \text { meses }\end{array}$ & 12 meses & $\mathbf{H b}$ & Ht & Hb \\
\hline $\begin{array}{l}\text { A - Fórmula infantil } \\
\text { fortificada com ferro }\end{array}$ & 20 & $9,1 \pm 0,29$ & $26,6 \pm 1,01$ & $11,2 \pm 0,16$ & $33,2 \pm 0,48$ & $11,6 \pm 0,16$ & $33,1 \pm 0,45$ \\
\hline $\begin{array}{l}\mathbf{B} \text { - Leite integral }+ \\
2 \mathrm{mg} \text { de ferro } / \mathrm{kg} / \mathrm{dia}\end{array}$ & 20 & $9,3 \pm 0,25$ & $27,3 \pm 0,72$ & $10,1 \pm 0,25$ & $30,0 \pm 0,66$ & $9,8 \pm 0,36$ & $30,6 \pm 0,89$ \\
\hline $\mathrm{p}$ & & 0,58 & 0,57 & 0,0026 & 0,002 & 0,00001 & 0,01 \\
\hline
\end{tabular}


Tabela 3 - Ferro sérico $(\mu \mathrm{g} / \mathrm{dl})$, TIBC ( $\mu \mathrm{g}$ Fe/dl) e protoporfirina eritrocitária livre - PEL ( $\mu \mathrm{g} / \mathrm{dl})$ aos 2 e 12 meses de idade (média \pm erro-padrão)

\begin{tabular}{|c|c|c|c|c|c|c|c|}
\hline \multirow{2}{*}{$\begin{array}{l}\text { Idade (meses) } \\
\text { Grupos }\end{array}$} & \multirow[b]{2}{*}{$\mathbf{N}$} & \multicolumn{2}{|c|}{ Ferro sérico } & \multicolumn{2}{|c|}{ TIBC } & \multicolumn{2}{|c|}{ PEL } \\
\hline & & $2 m$ & $12 \mathrm{~m}$ & $2 m$ & $12 \mathrm{~m}$ & $2 m$ & $12 \mathrm{~m}$ \\
\hline $\begin{array}{l}\text { A - Fórmula infantil } \\
\left.\text { fortificada (NAN2 }{ }^{\circledR}\right)\end{array}$ & 20 & $78,0 \pm 6,5$ & $74,7 \pm 7,3$ & $277 \pm 19$ & $349 \pm 14$ & $25,4 \pm 5,1$ & $28,1 \pm 2,6$ \\
\hline $\begin{array}{l}\text { B - Leite integral }+2 \mathrm{mg} \\
\text { ferro } / \mathrm{kg} / \text { dia (gotas) }\end{array}$ & 20 & $73,0 \pm 7,7$ & $47,1 \pm 4,8$ & $275 \pm 16$ & $385 \pm 30$ & $21,8 \pm 4,0$ & $53,5 \pm 10,7$ \\
\hline $\mathrm{p}$ & & 0,62 & 0,002 & 0,92 & 0,28 & 0,93 & 0,02 \\
\hline
\end{tabular}

$\mathrm{N}=$ número de crianças $\mathrm{m}=$ meses.

Também o número de perdas (26) e substituições, aparentemente grande, está dentro dos percentuais observados em trabalhos semelhantes ${ }^{9}$, que é em torno de $30 \%$ $40 \%$, tendo sido devido principalmente ao abandono do seguimento por mudança da família para municípios longínquos e que impossibilitou a regularidade dos retornos para avaliação e fornecimento do leite e/ou medicamentos.

As dietas lácteas oferecidas às crianças após o segundo mês de vida, em que pese poderem não ser consideradas ideais, não lhes impôs quaisquer sobrecargas metabólicas e digestivas, nem carências nutritivas, pois nas diluições utilizadas e nos volumes oferecidos não ultrapassavam $4 \mathrm{~g}$ de proteína por quilo por dia, eram bem balanceadas em hidratos de carbono e lipídeos, propiciando aporte calórico suficiente e não excessivo às crianças, o que lhes propiciou adequado ganho ponderal.

Quanto à alimentação complementar orientada, não é a recomendada atualmente ${ }^{23}$, que prevê a introdução de sólidos, mesmo nas crianças em aleitamento artificial, em torno do sexto mês de vida. Contudo, por ter sido prescrita a ambos os grupos, não influenciou os resultados, além de que a antecipação da introdução desses complementos foi de apenas um mês de idade cronológica, pois a idade gestacional média dos dois grupos foi de cerca de 33 semanas.

É importante que se esclareça que, na impossibilidade de se contar com o aleitamento materno para a alimentação de lactentes, inclusive de prematuros, o nosso estado e/ou municípios da nossa região disponibilizam, quando o fazem, leite de vaca in natura ou em pó, geralmente sem adições, o que nãoé ideal, mas que em diluições adequadas, adição de 3 a $5 \%$ de hidratos de carbono, suplementação de vitaminas e ferro, pode proporcionar bom desenvolvimento a essas crianças, que sem esse apoio acabariam por apresentar déficits nutricionais mais graves.

Quanto ao uso do NAN $2{ }^{\circledR}$, optou-se por ele por ter maior teor de ferro $(11 \mathrm{mg} \mathrm{Fe} / \mathrm{l})$ que as fórmulas para o primeiro semestre, que têm de 6 a $8 \mathrm{mg}$ de ferro/litro reconstituído; e por obedecer às especificações vigentes do
Codex Alimentarius FAO/OMS para fórmulas infantis, devendo-se estimular a indústria brasileira a disponibilizar fórmulas infantis específicas para alimentação pós-alta de prematuros.

Quanto à composição dos grupos, no que tange ao peso ao nascer, dieta e suplemento de ferro recebido durante o período de hospitalização e o número de transfusões de hemácias recebidas, pode-se considerá-los como bastante semelhantes e sem diferenças significativas, como aliás foi verificado no cotejo dos níveis iniciais de hemoglobina, hematócrito, ferro sérico, TIBC, PEL e ferritina, que não diferiam significantemente entre os grupos.

Analisando, nas idades posteriores, os vários índices estudados, sobre os quais a influência do aumento da volemia, da diluição em si, foi similar nos dois grupos, pois ambos triplicaram seus pesos iniciais (Tabela 1), pode-se verificar que as crianças do grupo A apresentaram hemoglobina e hematócrito significantemente mais elevados que as do grupo B já aos seis meses, o que se acentuou aos 12 meses de idade, evidenciando maior efetividade da fórmula fortificada com ferro na prevenção da anemia tardia dos prematuros que a administração diária de $2 \mathrm{mg}$ de ferro por quilo, na forma de gotas.

Aos 12 meses, verificou-se que os níveis de ferro sérico eram significativamente mais elevados nas crianças do grupo A, o que contribuiu para índices de saturação de TIBC também mais elevados e bem acima do nível mínimo tolerado para a idade (12\%), enquanto que $50 \%$ dos que receberam o ferro em gotas (grupo B) tinham saturação igual ou abaixo deste, evidenciando melhor estado nutritivo relativo ao ferro no grupo A.

Quanto à PEL, verificou-se que aos 12 meses as crianças do grupo B apresentaram níveis significativamente mais elevados que os seus próprios aos dois meses e em relação aos do grupo A, mostrando claros indícios de deficiência de ferro para síntese de hemoglobina nessa idade, confirmada pelos menores níveis de hematócrito e hemoglobina nas crianças deste grupo. Já os depósitos de ferro, avaliados pela ferritina, mostraram-se exauridos $(<10 \mathrm{mg} / \mathrm{ml})$ aos 12 
meses de idade, na maioria das crianças do grupo B, confirmando a maior eficácia da suplementação de ferro através da fórmula fortificada.

Poder-se-ia questionar que a dose de $2 \mathrm{mg} / \mathrm{kg} /$ dia seria insuficiente para prematuros de muito baixo peso $(<1.500 \mathrm{~g})$ e que isso até poderia ter implicações éticas. Contudo, apesar das recomendações de conhecidos estudiosos sobre $\mathrm{o}$ assunto ${ }^{12,13}$, de que a suplementação para prematuros de muito baixo peso e extremos deveria ser maior, de $2-4 \mathrm{mg} /$ $\mathrm{kg} / \mathrm{dia}$, o Comitê de Nutrição da AAP e a ESPGAN ${ }^{10,11,26}$ não alteraram a recomendação de $2 \mathrm{mg} / \mathrm{kg} / \mathrm{dia}$, certamente por não disporem de estudos definitivos a respeito, além do que cada vez mais tem ficado evidente a eficácia de fórmulas infantis fortificadas com teores de ferro de $6,9,11$ ou $12 \mathrm{mg} / \mathrm{litro}{ }^{24-26}$, que oferecem bem menos que $2 \mathrm{mg}$ de ferro/kg/dia, na prevenção da carência de ferro e da anemia tardia em prematuros, inclusive nos de muito baixo peso.

Assim, o presente estudo, mesmo com as limitações inerentes a ensaios clínicos de longa duração e com as dificuldades de se controlar rigidamente todas as variáveis envolvidas na avaliação, demonstrou que a suplementação de ferro a prematuros através de fórmula infantil fortificada com $11 \mathrm{mg}$ de ferro por litro foi incontestavelmente mais eficaz que a suplementação através de gotas de sulfato ferroso na dose de $2 \mathrm{mg} / \mathrm{kg} / \mathrm{dia}$, em uma única tomada, podendo-se aventar como explicação a ingestão regular e fracionada do nutriente através da fórmula ao longo do dia, que propiciaria maior taxa de absorção do metal.

Com base nestes resultados, de outros estudos recentes $^{24,25}$, nas evidências de segurança e boa tolerabilidade a fórmulas fortificadas com ferro com até $15 \mathrm{mg} / \mathrm{litro}^{25}$ e na menor eficácia da suplementação diária por gotas ${ }^{9}$, devese, na impossibilidade de ser mantida a amamentação a prematuros, fornecer-lhes fórmulas infantis fortificadas com ferro ao invés de leite de vaca in natura ou em pó não fortificado. A suplementação por gotas seria reservada às crianças em aleitamento natural, pois apesar da boa biodisponibilidade desse nutriente no leite humano, sua quantidade é insuficiente, mesmo para nascidos a termo e alimentados exclusivamente ao seio ${ }^{6,27}$.

\section{Referências bibliográficas}

1. United Nations, Administrative Committee on Coordination Subcommittee on Nutrition. Second Report on the World Nutrition Situation. World Health Organ Tech Rep Ser; 1992. p.40-8.

2. Lönnerdal B, Dewey KG. Epidemiologia da deficiência de ferro no lactente e na criança. Anais Nestlé 1996;52:11-19.

3. Walter T, De Andraca I, Chadud P, Perales CG. Iron deficiency anemia: adverse effects on infant psychomotor development. Pediatrics 1989;84:7-17.

4. Lozoff B, Jimenez E, Wolf A. Long-term developmental outcome of infants with iron deficiency. N Engl J Med 1992;326:575-6.

5. Lozoff B, Jimenez E, Hagen J, Mollen E, Wolf AW. Poorer behavioral and developmental outcome more than 10 years after treatment for iron deficiency in infancy. Pediatrics 2000;105:1-11.
6. Siimes MA, Salmenperä L, Perheentupa J. Exclusive breast-feeding for 9 months: risk of iron deficiency. J Pediatr 1984;104:196-9.

7. Torres MAA, Sato K, Souza Queiroz S. Anemia em crianças menores de 2 anos atendidas nas Unidades Básicas de Saúde no Estado de São Paulo. Rev Saúde Públ 1994;4:290-4.

8. Torres MAA, Sato K, Lobo NF, Souza Queiroz S. Efeito do uso de leite fortificado com ferro e vitamina $\mathrm{C}$ nos níveis de hemoglobina e condição nutricional de crianças menores de 2 anos. Rev Saúde Públ 1995;4:301-7.

9. Borigato EV, Martinez FE. Iron nutritional status in Brazilian preterm infants fed food cooked in iron pots. J Nutr 1998;128 :855-9.

10. American Academy of Pediatrics Committee on Nutrition. Nutritional needs of low-birth-weight infants. Pediatrics 1985;75:976-86.

11. European Society of Pediatric Gastroenterology and Nutrition. Nutrition and feeding of preterm infants. Acta Pediatr Scand 1987;336 (Supl):1-14.

12. Oski FA. Iron deficiency in infancy and childhood. N Eng J Med 1993;329:190-3.

13. Siimes MA, Järvenpää AL. Prevention of anemia and iron deficiency in very-low-birth-weight infants. J Pediatr 1982;101:277-80.

14. Fomon SJ, Nelson SE, Ziegler EE. Retention of iron by infants. Annu Rev Nutr 2000;20:273-90.

15. Torres MAA, Lobo NF, Sato K, Souza Queiroz S. Fortificação do leite fluido na prevenção e tratamento da anemia carencial ferropriva em crianças menores de 04 anos. Rev Saúde Públ 1996;30: 350-7.

16. Capurro H, Konichesky S, Fonseca D, Caldeyro-Barcia RA. Simplified method for diagnosis of gestational age in the newborn infant. J Pediatr 1978;93:120-4.

17. Woiski JR. Alimentação do lactente. In: Woiski JR, editores. Nutrição e dietética em pediatria. $4^{a}$ ed. São Paulo: Atheneu; 1995. p.109-26.

18. Dallman PR. Diagnóstico laboratorial da deficiência de ferro no lactente e na criança pequena. Anais Nestlé 1995;52:18-24.

19. Ramsay WNM. The determination of iron in blood plasma or serum. Clin Chim Acta 1957;12:214-20.

20. Faggioni LG. Contribuição para o estudo do metabolismo de ferro em crianças desnutridas [tese]. Ribeirão Preto: Universidade de São Paulo; 1969.

21. Piomelli S. A micromethod for free erythrocyte porphyrins: the FEP test. J Lab Clin Med 1973;81:932-40.

22. Berquó E. Bioestatística. $1^{a}$ ed. EDUSP: São Paulo; 1969.

23. Giugliani ERJ, Victora CG. Alimentação complementar. J Pediatr (Rio J) 2000;76(Supl 3):S253-62.

24. Griffin IJ, Cooke RJ, Reid MM, Mc Cormick KPB, Smith JS. Iron nutritional status in preterm infants fed formulas fortified with iron. Arch Dis Child Fetal Neonatal Ed 1999;81:45-9.

25. Franz AR, Mihatsch WA, Sander S, Kron M, Pohlandt F. Prospective randomized trial of early versus late enteral iron supplementation in infants with a birth weight of less than 1301 grams. Pediatrics 2000;106:700-6.

26. American Academy of Pediatrics. Committee on Nutrition. Iron fortification of infant formulas. Pediatrics 1999;104:119-23.

27. Pisacane A, De Vizia B, Valiante A. Iron status in breast-fed infants. J Pediatr 1995;127:429-31.

Endereço para correspondência:

Dra. Gisele Maria Couto Vianna

Rua Aracaju, 821 - Centro

CEP 15801-150 - Catanduva, SP

Fone: (17) 522.6322 / Fax: (017) 522.0550

E-mail: giselemari@zup.com.br 